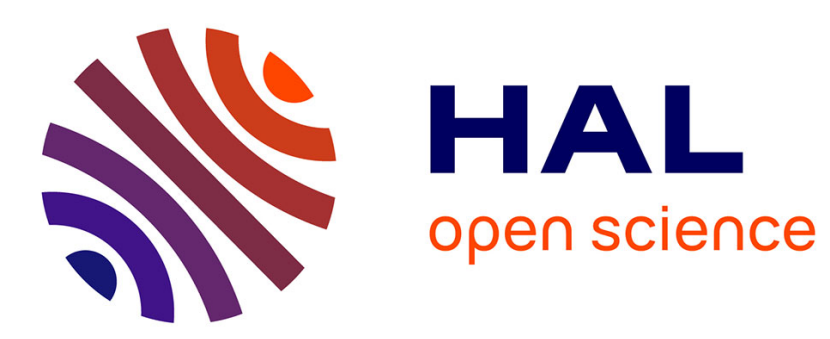

\title{
Inferred ground motions on Guadeloupe during the 2004 Les Saintes earthquake
}

\author{
John Douglas
}

\section{To cite this version:}

John Douglas. Inferred ground motions on Guadeloupe during the 2004 Les Saintes earthquake. Bulletin of Earthquake Engineering, 2007, 5 (3), pp.363-376. 10.1007/s10518-007-9037-2 . hal-00557615

\section{HAL Id: hal-00557615 https://hal-brgm.archives-ouvertes.fr/hal-00557615}

Submitted on 19 Jan 2011

HAL is a multi-disciplinary open access archive for the deposit and dissemination of scientific research documents, whether they are published or not. The documents may come from teaching and research institutions in France or abroad, or from public or private research centers.
L'archive ouverte pluridisciplinaire $\mathbf{H A L}$, est destinée au dépôt et à la diffusion de documents scientifiques de niveau recherche, publiés ou non, émanant des établissements d'enseignement et de recherche français ou étrangers, des laboratoires publics ou privés. 


\title{
Inferred ground motions on Guadeloupe during the 2004 Les Saintes earthquake
}

\author{
John Douglas \\ ARN/RIS, BRGM, 3 avenue C. Guillemin, BP 36009, 45060 Orléans Cedex 2, France.
}

March 29, 2007

\begin{abstract}
Accurate estimates of the ground motions that occurred during damaging earthquakes are a vital part of many aspects of earthquake engineering, such as the study of the size and cause of the uncertainties within earthquake risk assessments. This article compares a number of methods to estimate the ground shaking that occurred on Guadeloupe (French Antilles) during the 21st November $2004\left(M_{w} 6.3\right)$ Les Saintes earthquake, with the aim of providing more accurate shaking estimates for the investigation of the sources of uncertainties within loss evaluations, based on damage data from this event. The various techniques make differing use of the available ground-motion recordings of this earthquake and by consequence the estimates obtained by the different approaches are associated with differing uncertainties. Ground motions on the French Antilles are affected by strong local site effects, which have been extensively investigated in previous studies. In this article, use is made of these studies in order to improve the shaking estimates. It is shown that the simple methods neglecting the spatial correlation of earthquake shaking lead to uncertainties similar to those predicted by empirical ground-motion models and that these are uniform across the whole of Guadeloupe. In contrast, methods (such as the ShakeMap approach) that take account of the spatial correlation in motions demonstrate that shaking within roughly $10 \mathrm{~km}$ of a recording station (covering a significant portion of the investigated area) can be defined with reasonable accuracy but that motions at more distant points are not well constrained.
\end{abstract}

Key words: ground-motion estimation; Guadeloupe; Les Saintes; ShakeMap; site effects; spatial correlation; strong ground motion; uncertainties

\section{Introduction}

This article has the simple aim of estimating the earthquake ground motion that occurred on the island group of Guadeloupe (French Antilles) during the damaging Les Saintes earthquake 
$\left(M_{w} 6.3\right)$ of 21 st November 2004. Thanks to previously published maps of expected site amplifications at all locations on the islands and also the recording of numerous accelerograms during this earthquake a number of previously proposed methods can be applied.

Le Brun et al. (2005) undertook a limited analysis to see whether the damage caused by the Les Saintes earthquake could have been accurately estimated using a relatively simple risk assessment technique. Work is currently underway to extend this study and to understand the uncertainties involved, using damage information from this earthquake as ground-truth data. One major contribution to the uncertainty within risk estimates is that coming from groundmotion estimation (e.g. Bommer and Crowley, 2006) although uncertainty in the building capacity parameters can be as important as those related to the shaking (e.g. Crowley et al., 2005). This article tries to provide more accurate estimates of the shaking that occurred during this earthquake in order to be able to more easily investigate other, often less important, factors influencing uncertainties within risk evaluation.

The estimation of shaking over a large region using observed ground motions from a damaging earthquake has been tackled in numerous studies, e.g.: for the 1971 San Fernando event (Carr et al., 1986), for the 1994 Northridge event (King et al., 2004; Jeon and O'Rourke, 2005, and references therein), for the 2000 Tottori-ken Seibu and 2001 Geiyo events (Shabestari et al., 2004) and for the 2004 Niigata Chuetsu earthquake (Suetomi et al., 2006), in addition to numerous studies making use of ground-motion simulation. ShakeMap (Wald et al., 2006) and similar recent projects combine real-time data and ground-motion models to automatically estimate shaking soon after an earthquake occurs for civil defence purposes.

Boore et al. (2003) undertake a detailed analysis in order to estimate the ground motions during the Northridge 1994 earthquake at the site of a road interchange collapse. Their approach relied upon detailed near-surface velocity profiles for the studied site and nearby strong-motion stations, which do not exist for sites on Guadeloupe. In addition, the relatively low density of the strong-motion networks on Guadeloupe means such an approach is not feasible for estimating the ground motions at all points on the island.

The focus of this article is the estimation of two strong-motion intensity parameters for the larger horizontal component: peak ground acceleration (PGA) and spectral acceleration at $1.0 \mathrm{~s}[\mathrm{SA}(1.0 \mathrm{~s})]$, which are useful for earthquake loss estimations since they approximately characterize the ground-motion amplitudes affecting short- and long-period structures. Estimates for other parameters (e.g. durations or cycle counting measures) could be derived using similar approaches.

The following section provides brief details of the characteristics of the Les Saintes earthquake including the observed damage. Next, a number of methods of ground-motion estimation 
to predict the shaking at all points on Guadeloupe are discussed and the obtained results presented. Applying a series of different methods based on a single ground-motion model and a relatively sparse set of accelerometric data allows a lower bound assessment of the epistemic uncertainty of the estimates. The article closes with a brief discussion and some conclusions.

\section{Les Saintes earthquake}

The Les Saintes earthquake occurred offshore of Guadeloupe about $20 \mathrm{~km}$ from the southern coast, close to the island group of Les Saintes on 21st November 2004 at 11:41:08 UTC (Centre de Données Sismologiques des Antilles, CDSA). Its moment magnitude $\left(M_{w}\right)$ was estimated to be 6.3 by both Harvard CMT and the USGS. According to Harvard CMT, the strike $(\phi)$, dip $(\delta)$ and rake $(\lambda)$ of the two planes are: $\phi_{1}=325^{\circ}, \delta_{1}=44^{\circ}, \lambda_{1}=-77^{\circ}, \phi_{2}=127^{\circ}, \delta_{2}=48^{\circ}$ and $\lambda_{2}=-102^{\circ}$ (similar parameters are reported by the USGS), which corresponds to normal faulting using the standard faulting mechanism classification schemes; see Bommer et al. (2003) for a summary of these methods. The earthquake was associated with rupture along a shallow fault (focal depth $14 \mathrm{~km}, \mathrm{CDSA}$ ). At present, there are no published fault models for this earthquake therefore all source-to-site distances used in this study are epicentral distances, $R_{\text {epi }}$.

This earthquake was associated with a maximum macroseismic intensity (EMS98) of VIII (Bureau Central Sismologique Français, BCSF) on the islands of Les Saintes. It caused significant damage to a number of buildings on Guadeloupe and triggered many landslides. A detailed analysis of this earthquake, associated phenomena (landslides and possible tsunamis) and its effects on buildings is presented by Bertil et al. (2005).

A description of the strong-motion networks installed on Guadeloupe and a list of operating stations is provided by Douglas et al. (2006). Table 1 presents a summary of the available ground-response strong-motion data from this earthquake (records from the upper storeys of structures are excluded). Dense strong-motion networks are also installed on Martinique (another island in the French Antilles) to the south of Guadeloupe and 24 records from the earthquake are available. However, due to the much greater distance to the earthquake source $\left(119 \leq R_{\text {epi }} \leq 157 \mathrm{~km}\right.$ ) ground motions were much smaller on this island (PGAs less than $0.02 \mathrm{~g})$. Therefore, this article is only seeks to estimate motions on Guadeloupe.

As shown in Table 1 the maximum PGA recorded during this earthquake was $2.09 \mathrm{~m} / \mathrm{s}^{2}$ $(0.21 \mathrm{~g})$ at an epicentral distance of $31 \mathrm{~km}$, although closer to the source, e.g. on the islands of the Les Saintes group, higher accelerations were probably experienced. Beresnev and Wen (1996) review evidence of nonlinear soil response during earthquakes and conclude that it 
Table 1: Available strong-motion data from the Les Saintes earthquake recorded on Guadeloupe and predicted ground motions via different methods. Also given is the overall bias and standard deviation of each method.

\begin{tabular}{|c|c|c|c|c|c|c|c|c|c|c|c|c|c|c|c|c|c|c|}
\hline \multirow[t]{2}{*}{$\#$} & \multirow[t]{2}{*}{ Station } & \multirow[t]{2}{*}{ Code } & \multirow[t]{2}{*}{$\mathrm{C}$} & \multirow{2}{*}{$\begin{array}{l}R_{\text {epi }} \\
(\mathrm{km})\end{array}$} & \multicolumn{7}{|c|}{ PGA $\left(\mathrm{m} / \mathrm{s}^{2}\right)$} & \multicolumn{7}{|c|}{$\mathrm{SA}(1.0 \mathrm{~s})\left(\mathrm{m} / \mathrm{s}^{2}\right)$} \\
\hline & & & & & $\mathrm{O}$ & $\mathrm{A}$ & $\mathrm{B}$ & $\mathrm{C}$ & $\mathrm{D}$ & $\mathrm{E}$ & $\mathrm{F}$ & $\mathrm{O}$ & A & $\mathrm{B}$ & $\mathrm{C}$ & $\mathrm{D}$ & $\mathrm{E}$ & $\mathrm{F}$ \\
\hline 1 & Grand-Bourg & GBGA & $\mathrm{R}$ & 24 & 1.54 & 0.71 & 1.53 & 2.16 & 3.23 & 2.37 & 1.74 & 1.36 & 0.48 & 0.89 & 1.00 & 1.53 & 1.29 & 1.44 \\
\hline 2 & Houëlmont-Gourbeyre & GHMA & $\mathrm{H}$ & 31 & 2.09 & 0.60 & 1.27 & 0.67 & 1.00 & 0.82 & 1.54 & 1.27 & 0.60 & 1.11 & 0.46 & 0.70 & 0.63 & 1.07 \\
\hline 3 & Préfecture & PRFA & $\mathrm{R}$ & 33 & 0.64 & 0.49 & 1.05 & 1.23 & 1.69 & 1.43 & 0.04 & 0.42 & 0.34 & 0.64 & 0.57 & 0.87 & 0.80 & 0.34 \\
\hline 4 & Belfond Saint-Claude & GJYA & $\mathrm{R}$ & 34 & 1.98 & 0.48 & 1.02 & 0.61 & 0.91 & 0.77 & 0.99 & 0.54 & 0.34 & 0.63 & 0.42 & 0.64 & 0.58 & 0.32 \\
\hline 5 & Ecole Pigeon & PIGA & $\mathrm{R}$ & 50 & 0.46 & 0.31 & 0.66 & 0.39 & 0.58 & 0.58 & 0.34 & 0.45 & 0.23 & 0.42 & 0.28 & 0.43 & 0.43 & 0.16 \\
\hline 6 & Institut Pasteur & IPTA & $\mathrm{R}$ & 51 & 0.40 & 0.30 & 0.64 & 0.91 & 1.36 & 1.38 & 0.54 & 0.34 & 0.22 & 0.41 & 0.46 & 0.70 & 0.71 & 0.30 \\
\hline 7 & Pointe-à-Pitre — Fengarol & GFEA & $\mathrm{S}$ & 52 & 0.84 & 0.40 & 0.87 & 0.75 & 1.12 & 1.15 & 0.78 & 0.87 & 0.50 & 0.92 & 0.80 & 1.22 & 1.23 & 1.18 \\
\hline 8 & Antéa Abymes & GBRA & $\mathrm{R}$ & 53 & 0.62 & 0.28 & 0.61 & 0.28 & 0.43 & 0.44 & 0.44 & 0.50 & 0.21 & 0.39 & 0.21 & 0.32 & 0.33 & 0.36 \\
\hline 9 & Pointe-à-Pitre — Lauricisque & GLAA & $\mathrm{S}$ & 53 & 1.29 & 0.39 & 0.84 & 0.73 & 1.09 & 1.13 & 1.20 & 2.39 & 0.48 & 0.90 & 0.78 & 1.19 & 1.21 & 2.23 \\
\hline 10 & Aéroport Glide (surface) & GGSA & $\mathrm{S}$ & 55 & 1.23 & 0.38 & 0.81 & 0.70 & 1.05 & 1.10 & 1.25 & 3.47 & 0.47 & 0.87 & 0.75 & 1.15 & 1.18 & 3.39 \\
\hline 11 & Morne à l'Eau & MESA & $\mathrm{S}$ & 62 & 0.51 & 0.33 & 0.70 & 0.24 & 0.36 & 0.39 & 0.52 & 0.29 & 0.41 & 0.76 & 0.18 & 0.27 & 0.29 & 0.31 \\
\hline 12 & Saint-Fran cois & SFGA & $\mathrm{R}$ & 62 & 0.33 & 0.24 & 0.51 & 0.24 & 0.36 & 0.40 & 0.34 & 0.25 & 0.18 & 0.33 & 0.18 & 0.27 & 0.29 & 0.26 \\
\hline 13 & Radar Météo Le Moule & MOLA & $\mathrm{R}$ & 62 & 0.29 & 0.24 & 0.51 & 0.24 & 0.36 & 0.40 & 0.31 & 0.30 & 0.18 & 0.33 & 0.18 & 0.27 & 0.29 & 0.29 \\
\hline 14 & Sainte-Rose & SROA & $\mathrm{R}$ & 65 & 1.09 & 0.22 & 0.48 & 0.28 & 0.42 & 0.48 & 1.10 & 0.36 & 0.17 & 0.32 & 0.21 & 0.32 & 0.35 & 0.37 \\
\hline 15 & Anse-Bertrand & BERA & $\mathrm{R}$ & 79 & 0.33 & 0.18 & 0.38 & 0.18 & 0.27 & 0.33 & 0.33 & 0.22 & 0.14 & 0.26 & 0.14 & 0.21 & 0.24 & 0.22 \\
\hline \multirow{2}{*}{\multicolumn{2}{|c|}{$\begin{array}{l}\text { Overall bias }(\mu) \\
\text { Standard deviation }(\sigma)\end{array}$}} & & & & & 0.33 & 0.00 & 0.18 & 0.00 & 0.00 & 0.14 & & 0.27 & 0.00 & 0.18 & 0.00 & 0.00 & 0.03 \\
\hline & & & & & & 0.20 & 0.20 & 0.27 & 0.27 & 0.27 & 0.32 & & 0.27 & 0.27 & 0.25 & 0.25 & 0.24 & 0.13 \\
\hline
\end{tabular}

$\mathrm{C}$ is site class ( $\mathrm{R}$ is rock, A is stiff soil, $\mathrm{S}$ is soft soil and $\mathrm{H}$ is hill); PGA is the peak ground acceleration, $\mathrm{SA}(1.0 \mathrm{~s})$ is the elastic spectral acceleration for $5 \%$ damping and a period of $1.0 \mathrm{~s}$, both for the larger horizontal component; $\mathrm{O}$ is observed amplitude; A is amplitude predicted using unadjusted model of Ambraseys et al. (2005); B is amplitude predicted using bias-corrected model of Ambraseys et al. (2005); C is amplitude predicted using model of Ambraseys et al. (2005) for rock and site amplifications from Bour et al. (2000) and Le Brun et al. (2001); D is amplitude predicted using bias-corrected model of Ambraseys et al. (2005) for rock and site amplifications from Bour et al. (2000) and Le Brun et al. (2001); E is amplitude predicted using an event-specific ground-motion model and site amplifications from Bour et al. (2000) and Le Brun et al. (2001); and $\mathrm{F}$ is amplitude predicted using the ShakeMap algorithm.

Stations: $1,3,5,6,11,12,13,14$ and 15 are part of the RAP-OSVG network operated by Institut de Physique du Globe de Paris (IPGP) and stations: 2, 4, 7, 8, 9 and 10 are part of the BRGM network. 
becomes apparent above a PGA of about $0.1-0.2 \mathrm{~g}$. In view of this, and because of limited knowledge, for the French Antilles, of the parameters required to model nonlinear soil response, in this article linear site effects are assumed for all sites.

\section{Methods ignoring the spatial correlation of shaking}

The most straightforward method to estimate the ground motions that occurred during this earthquake is to use published ground-motion prediction equations (GMPEs) (e.g. Douglas, 2003). Currently there are no peer-reviewed GMPEs developed specifically for the French Antilles in the literature and hence models developed for other regions must be adopted or adapted. Using recorded strong-motion data Douglas et al. (2006) examine the suitability of different GMPEs for the estimation of shaking on the French Antilles using the methodology proposed by Scherbaum et al. (2004). They find that none of the models considered are well adapted to the prediction of ground motions from shallow crustal earthquakes, however, the model of Ambraseys et al. (2005) provides, in general, the best fit to observed shaking. Hence, this model is used here although it should not be expected to give very accurate results because it does not, in general, closely predict observed shaking on the French Antilles. The results from most of the methods considered here are strongly dependent on the choice of the underlying GMPEs.

Figures 1 and 2 present PGA and SA(1.0 s) on Guadeloupe predicted by the various methods considered here. This section discusses these methods and their uncertainties. For the simple methods presented in the following three sections the uncertainties at points far from the recording stations are difficult to assess. A basic estimate of the uncertainties within this method can be obtained from the residuals, i.e. the differences between common logarithms of observed and predicted motions. The overall bias (the mean of the residuals) and its standard deviation for the different methods are reported in Table 1. The standard deviations are similar to those of standard empirical ground-motion models, e.g. the standard deviation of the model of Ambraseys et al. (2005) for PGA is 0.27 and for $\mathrm{SA}(1.0 \mathrm{~s})$ it is 0.33 for an $M_{w} 6.3$ earthquake, such as Les Saintes.

[Figure 1 about here.]

[Figure 2 about here.]

\subsection{Unadjusted empirical ground-motion models}

In this approach ground motions are evaluated using the model of Ambraseys et al. (2005) after having classified sites into the categories used by this model. Since not all sites on Guadeloupe 
have been classified into the categories used by Ambraseys et al. (2005) a map of predicted ground motions using this method cannot be shown, however, Table 1 presents the results obtained using this method for the 15 accelerometric stations.

\subsection{Unadjusted empirical ground-motion models on rock plus site effects}

Possible site amplifications on Guadeloupe have been well studied during various projects (e.g. Lebrun et al., 2004, and references therein). These projects have shown that site amplifications on these islands can be large and highly variable between sites with similar surface geology. This means that a more accurate method than used above is to predict ground motions on rock and then multiply these motions by the expected site amplifications at each site. This method should more accurately predict motions at sites with complex site effects that cannot be predicted by the relatively simple methods for the inclusion of site effects within empirical GMPEs, where sites are generally classified into a handful of classes. Bour et al. (2000) classify sites on Guadeloupe into nine classes based on published geological maps, microzonations and other information and then they conduct site response analysis for generic soil profiles corresponding to these classes using natural and synthetic accelerograms appropriate for Guadeloupe. From the resulting response spectra, they derive design spectral shapes for five different classes of site (by combining similar results for the nine original classes) and they also present PGA amplification factors for the different classes of site. Le Brun et al. (2001) slightly modify and simplify these amplification factors; their amplifications are used here. For SA(1.0s) the site amplification factors used are those given by combining the PGA factors of Le Brun et al. (2001) with the spectral shapes of Bour et al. (2000) for each of the five classes. The uncertainties within the shaking estimates at each site are estimated as above (Table 1). The benefit of using the local site amplification factors provided by Bour et al. (2000) and Le Brun et al. (2001) is demonstrated by the lower biases obtained, although the variability is increased for PGA suggesting that the site factors for some stations may not be appropriate.

\subsection{Empirical ground-motion model specifically for Les Saintes earthquake}

As noted above, Douglas et al. (2006) find that none of the GMPEs examined accurately predict observed ground motions during earthquakes recorded on Guadeloupe, which is specifically shown for the Les Saintes event by the large biases obtained using the two methods above. One simple method to provide more accurate ground-motion estimates is to adjust the median ground motions estimated by the model of Ambraseys et al. (2005) to obtain a zero bias, i.e. to correct for average under- or over-estimation. Accelerometers on Guadeloupe are located on sites of various classes, therefore, the observed ground motions are converted to the estimated 
ground motion for a rock site using the site effect factors of Bour et al. (2000) and Le Brun et al. (2001). It is assumed that this bias adjustment, based on the predicted and observed motions, accurately accounts for the true inter-event variation, but since data from only 15 stations is used this may not be true. Multiplication of the predicted motions of Ambraseys et al. (2005) by factors equal to the reciprocal of the anti-logarithms of the overall bias removes this bias but does not reduce the standard deviations (Table 1).

This adjustment will not model a different rate of decay of ground motions or higher or lower average site amplifications during the Les Saintes earthquake than predicted by the GMPEs of Ambraseys et al. (2005). Such effects could be included by the derivation and use of an event specific ground-motion model, such as computed by Campbell (1991) for the Loma Prieta 1989 earthquake. One problem with this approach for the Les Saintes event is that there is little data available to constrain the coefficients of the equation and, in addition, the distribution of data with respect to distance and azimuth is relatively poor. As above, the observed motions are converted to estimated rock motions using the site effect factors of Bour et al. (2000) and Le Brun et al. (2001) in order to derive the event-specific model. Since there are only 15 data points from Guadeloupe available, the simple functional form:

$$
\log y=a+b \log \sqrt{R_{\mathrm{epi}}^{2}+5^{2}}
$$

is selected and linear regression is performed. Since there is no close-in data to constrain the near-source behaviour of the fitted curve, $5 \mathrm{~km}$ is chosen in order that predicted ground motions near the epicentre are constrained $[5 \mathrm{~km}$ is close to the usual value for this coefficient (e.g. Ambraseys et al., 2005)]. The exact value of this coefficient does not strongly affect the predicted motions for sites on Guadeloupe because of the relatively large source-to-site distances involved. The coefficients of the derived equations are not reported here since these equations are not robust and their application in seismic hazard analysis is not encouraged. Table 1 reports the computed bias and standard deviation of this approach, showing that the bias is removed but the standard deviation remains high.

\section{Methods considering the spatial correlation of shaking}

The methods described and implemented above do not make best use of the available strongmotion data mainly because they do not take account of spatial variability except that related to differences in source-to-site distances. In addition, shaking estimates for each point on Guadeloupe are associated with the same uncertainty irrespective of the density of accelerometers in the surrounding area. For example, the ground motion at the site of an accelerometer is 
known exactly whereas that at a site many kilometres distant is more uncertain. The methods discussed in this section require a good spatial distribution of strong-motion stations, unlike the simple techniques discussed above.

As in the approaches above, and similarly to the approach adopted by ShakeMap (Wald et al., 2006), ground motions at each strong-motion station are converted to the estimated ground motion at a rock site by dividing by the expected site amplification at the station. These 'rock' motions are then processed using the interpolation methods discussed below. After interpolation the site amplifications of Bour et al. (2000) and Le Brun et al. (2001) are applied to the predicted 'rock' motions to obtain the ground motions including site effects.

\subsection{Universal kriging}

Ambraseys and Douglas (2004) apply the geostatistical method known as kriging to macroseismic intensity data of North Indian earthquakes. This technique estimates the value of a parameter at a location of interest through the computation of a weighted average with weights dependent on the geographical distance between the site and observation points. Since earthquake ground motions, in general, decay with increasing source-to-site distance the method known as universal kriging (kriging with a drift model) was adopted since this takes into account underlying trends in the data. This method was applied to recorded ground motions from the Les Saintes event using an exponential semi-variogram as used by Ambraseys and Douglas (2004) and a value of $a$ (roughly describing the distance at which points become uncorrelated) of $100 \mathrm{~km}$, which is in agreement with the findings of Wang and Takada (2005).

\subsection{Adapted method of King et al. (2004)}

A technique is developed by King et al. (2004) to estimate the strong ground motions (PGA and response spectra) at 50 sites within the epicentral region of the Northridge 1994 earthquake based on observed data and ground-motion models. The Northridge earthquake was very well recorded by dense strong-motion networks (records about every $3 \mathrm{~km}$ ). In comparison, there are 15 records from Guadeloupe available for this study, corresponding to a record about every $10 \mathrm{~km}$. In addition, as noted above there are, at present, no peer-reviewed ground-motion models well adapted for the prediction of shaking from shallow crustal earthquakes in the French Antilles (Douglas et al., 2006). Therefore it is necessary to slightly modify the method proposed by King et al. (2004).

As in the method of King et al. (2004), normalised weights are computed for each location on the island that are inversely proportional to the distance from the site to surrounding stations. As a result of the lower density of stations on Guadeloupe in comparison to Los Angeles and 
since this method is applied for thousands of points [rather than for only 50 sites as in King et al. (2004)], all stations were used in this weighting process rather than simply those within a few kilometres [as done by King et al. (2004)]. However, the difference in the results when using all stations rather than only those closest is not large due to weights that are inversely proportional to separation distance. After this weighting of the observed ground motions, the predicted amplitudes are corrected for differences in source-to-site distances between the weighted geographic centroid of the stations and the site by using the GMPEs of Ambraseys et al. (2005). Since the GMPEs are only used for correcting for differences in source-to-site distances the choice of ground-motion model does not have a large influence on the obtained results.

The ground motions predicted by this method are similar to those predicted by the universal kriging method described above. This is unsurprising since the two approaches are comparable: weighted average of observed ground motions at surrounding points corrected for attenuation from the source, although the weighting and attenuation functions used differ in the two techniques.

\subsection{ShakeMap method}

Wald et al. (2006) describe the ShakeMap method that computes near real-time estimates of ground motions. An adaption of this method was tested here for the Les Saintes earthquake. This approach uses observed ground motions for locations close to strong-motion stations and then event-adjusted GMPEs for locations on a regular grid far from accelerometers; between these two extremes an interpolation technique is adopted. As within the standard ShakeMap method the ground motions predicted by the selected underlying GMPEs of Ambraseys et al. (2005) are corrected for bias using the same factors as computed above. In order to obtain reasonable estimated ground motions at all sites on Guadeloupe it was necessary to decrease the spacing of the grid to $10 \mathrm{~km}$ from the default of $30 \mathrm{~km}$. The choice of GMPEs used for predicting ground motions at the points on the regular grid has a significant impact on the predicted motions at points distant from the strong-motion stations.

The shaking predicted by the ShakeMap method is similar to that predicted by the two other methods combining interpolation of observed ground motions discussed above although it shows more variation over the islands. Similar ground motions close to stations are estimated by all three techniques but the various approaches used for estimating motions at points far from the recording stations leads to larger differences at sites distant from observation points. 


\subsection{Accuracy of estimated ground motions}

The ground motions at each observation point are predicted exactly by kriging and in the method of King et al. (2004), therefore a different method has to be used to assess the uncertainties in the computed ground motions. Boore et al. (2003) present the following equation to estimate the standard deviation of differences in the logarithm of peak motion, $\sigma_{\Delta \log Y}$, as a function of the separation distance between stations, $\Delta$ :

$$
\begin{aligned}
\sigma_{\Delta \log Y}^{2} & =\sigma_{\text {indobs }}^{2}\left(1+\frac{1}{N}\right) F(\Delta)^{2} \\
\text { where } F(\Delta) & =1-\exp (-\sqrt{0.6 \Delta})
\end{aligned}
$$

where $\sigma_{\text {indobs }}^{2}$ is the intra-event standard deviation of a GMPE and $N$ is the number of recordings used in the average of a group of recordings. This equation was used by Lin et al. (2006) to quantify the uncertainty in the ShakeMap estimates. For PGA the GMPE of Ambraseys et al. (2005) has a intra-event standard deviation of 0.26 for a $M_{w} 6.3$ earthquake and for $\mathrm{SA}(1.0 \mathrm{~s})$ the intra-event standard deviation is 0.31 . Only the intra-event variability is considered, here, since the GMPEs of Ambraseys et al. (2005) have been corrected for event bias. In this article, a point source has been assumed for the Les Saintes earthquake. Lin et al. (2006) note that this assumption leads to additional uncertainty in the estimated ground motions since earthquakes are generally non-point sources. The equation of Wells and Coppersmith (1994) for the estimation of subsurface fault length for a $M_{w} 6.3$ normal-mechanism event, such as Les Saintes, gives $19 \pm 7 \mathrm{~km}$, therefore the source-to-site distances assumed here are uncertain. Using the equations presented by Lin et al. (2006) the additional uncertainties $\left(\sigma_{\text {add }}\right)$ in assuming a point source are between 0.10 (for $R_{\text {epi }}=10 \mathrm{~km}$ ) and 0.02 (for $R_{\text {epi }}=100 \mathrm{~km}$ ) for PGA and between 0.09 (for $R_{\text {epi }}=10 \mathrm{~km}$ ) and 0.02 (for $R_{\text {epi }}=100 \mathrm{~km}$ ) for $\mathrm{SA}(1.0 \mathrm{~s}$ ), which are used in conjunction with the intra-event standard deviations for the model of Ambraseys et al. (2005) thus: $\sigma_{T}=\sqrt{\sigma_{\text {indobs }}^{2}+\sigma_{\text {add }}^{2}}$. Figure 3 shows $\sigma_{T}$ computed by this method for the two strong-motion intensity parameters considered.

[Figure 3 about here.]

Figure 3 demonstrates that the additional uncertainty due to assuming a point source for this earthquake does not have a important influence on the estimated accuracy of predicted motions. Due to the relatively uniform spacing of strong-motion stations on Guadeloupe the predicted motions are associated with lower aleatoric variability at most points on the islands than would be assumed by neglecting the spatial correlation of shaking. Unfortunately ground motions on the Les Saintes group of islands and on much of Basse Terre (the western part of 
Guadeloupe) where most damage from this event was observed are relatively poorly constrained due to the lack of nearby records.

\section{Conclusions}

This article had the simple aim of estimating the strong-motion intensity measures PGA and SA(1.0s) for 5\% damping on Guadeloupe from the 21st November 2004 Les Saintes earthquake $\left(M_{w} 6.3\right)$. A number of different methods to estimate these strong-motion parameters were applied in order to understand the improvement in accuracy that could be obtained by using more sophisticated methods. A future goal is to use these estimated ground motions as input to analyse the damage that occurred on Guadeloupe during this earthquake and consequently to understand the uncertainties in earthquake risk models that have been developed for the French Antilles.

It is found that simple methods neglecting the spatial correlation of ground motions predict motions at accuracies similar to the underlying empirical ground-motion model used and also that the predicted ground motions are strongly dependent on the GMPEs chosen. This approach, however, assumes that all shaking estimates are associated with a uniform uncertainty even at locations close to recording stations. The more sophisticated approaches taking account of the spatial correlation in earthquake ground motions demonstrate that estimated grounds motions close to strong-motion stations are associated with low aleatoric variabilities (Figure 3) and also low epistemic uncertainties because the three different procedures predict similar motions. On the other hand, at locations more than $10 \mathrm{~km}$ from the nearest strongmotion station (covering the Les Saintes group closest to the epicentre and much of Basse Terre and Marie Galante) the shaking that occurred during the Les Saintes mainshock is not well constrained since the different approaches predict varying motions and, in addition, the large generally-observed variability in earthquake shaking cannot be reduced by appealing to the proximity to a recording station. In order to reduce these uncertainties it would be useful to conduct ground-motion simulations taking account of the complexity of the earthquake source, the crustal structure and the important site effects on Guadeloupe. Such simulations would enable the motions at points distant from strong-motion stations and in the near-source area to be better constrained. However, results from simulations are also uncertain due to the techniques used and also limited knowledge of the required source, path and site input parameters hence, without a high density of instruments, the shaking at a given site will remain unknown. Trifunac and Todorovska (2001) argue that at least a two-order-magnitude increase in the general density of strong-motion instrumentation (corresponding to instruments about every 
$1 \mathrm{~km}$ ) is required to be able to adequately capture spatial variations in earthquake shaking; this is also demonstrated by Figure 3 .

\section{Acknowledgements}

This study was funded by BRGM research projects. The strong-motion networks on Guadeloupe are operated by BRGM and the Institut de Physique du Globe de Paris (IPGP), which is under the aegis of the Réseau Accélérometrique Permanent (RAP) of France. The RAP data centre is based at Laboratoire de Géophysique Interne et de Tectonophysique, Grenoble. I am very grateful to the personnel of these organisations for operating the stations and providing me with the data, without which this study would have been impossible. I thank Olivier Sedan for providing the electronic version of the site effect map of Bour et al. (2000) and Le Brun et al. (2001). A careful and detailed review by Julian Bommer led to significant improvements to this article.

\section{References}

N. N. Ambraseys and J. Douglas. Magnitude calibration for north Indian earthquakes. Geophysical Journal International, 159(1):165-206, 2004. doi: 10.1111/j.1365-246X.2004.02323.x.

N. N. Ambraseys, J. Douglas, S. K. Sarma, and P. M. Smit. Equations for the estimation of strong ground motions from shallow crustal earthquakes using data from Europe and the Middle East: Horizontal peak ground acceleration and spectral acceleration. Bulletin of Earthquake Engineering, 3(1):1-53, 2005. doi: 10.1007/s10518-005-0183-0.

I. A. Beresnev and K.-L. Wen. Nonlinear soil response - a reality? Bulletin of the Seismological Society of America, 86(6):1964-1978, Dec 1996.

D. Bertil, S. Bes De Berc, and J. Douglas. Synthèse de la crise sismique des Saintes (Guadeloupe) entre le 21 novembre 2004 et le 30 mars 2005. Final report RP-54401-FR, BRGM, France, 2005. URL http://www.brgm.fr/publication/rechRapportSP.jsp.

J. J. Bommer and H. Crowley. The influence of ground-motion variability in earthquake loss modelling. Bulletin of Earthquake Engineering, 4(3):231-248, 2006. doi: 10.1007/s10518006-9008-z.

J. J. Bommer, J. Douglas, and F. O. Strasser. Style-of-faulting in ground-motion prediction equations. Bulletin of Earthquake Engineering, 1(2):171-203, 2003. 
D. M. Boore, J. F. Gibbs, W. B. Joyner, J. C. Tinsley, and D. J. Ponti. Estimated ground motion from the 1994 Northridge, California, earthquake at the site of the Interstate 10 and La Cienega Boulevard bridge collapse, west Los Angeles, California. Bulletin of the Seismological Society of America, 93(6):2737-2751, Dec 2003.

M. Bour, H. Fabriol, O. Monge, and O. Sedan. XIème CPER Guadeloupe: Evaluation des mouvements sismiques locaux à l'échelle régionale (cas du séisme lointain et du comportement linéaire équivalent). Technical Report R40897, BRGM, France, Mar 2000. URL wWw.brgm.fr/publication/rechRapportSP.jsp.

K. W. Campbell. An empirical analysis of peak horizontal acceleration for the Loma Prieta, California, earthquake of 18 October 1989. Bulletin of the Seismological Society of America, 81(5):1838-1858, Oct 1991.

J. R. Carr, E. D. Deng, and C. E. Glass. An application of disjunctive kriging for earthquake ground motion estimation. Mathematical Geology, 18(2):197-213, 1986.

H. Crowley, J. J. Bommer, R. Pinho, and J. Bird. The impact of epistemic uncertainty on an earthquake loss model. Earthquake Engineering and Structural Dynamics, 34(14):1653-1685, Nov 2005. doi: 10.1002/eqe.498.

J. Douglas. Earthquake ground motion estimation using strong-motion records: A review of equations for the estimation of peak ground acceleration and response spectral ordinates. Earth-Science Reviews, 61(1-2):43-104, 2003.

J. Douglas, D. Bertil, A. Roullé, P. Dominique, and P. Jousset. A preliminary investigation of strong-motion data from the French Antilles. Journal of Seismology, 10(3):271-299, 2006. doi: 10.1007/s10950-006-9016-0.

S.-S. Jeon and T. D. O'Rourke. Northridge earthquake effects on pipelines and residential buildings. Bulletin of the Seismological Society of America, 95(1):294-318, Feb 2005. doi: $10.1785 / 0120040020$.

S. A. King, A. Hortacsu, and G. C. Hart. Post-earthquake estimation of site-specific strong ground motion. In Proceedings of Thirteenth World Conference on Earthquake Engineering, 2004. Paper no. 2834.

B. Le Brun, O. Monge, M. Bour, O. Sedan, and C. Mirgon. XI Contrat de Plan Etat - Région Guadeloupe relatif à l'évaluation et la prévention du risque sismique: Définition des séismes de scénario et résultats des simulations. Technical Report BRGM/RP-50798-FR, BRGM, France, 2001. URL www.brgm.fr/publication/rechRapportSP.jsp. 
B. Le Brun, O. Sedan, C. Mirgon, and D. Bertil. Simulation of damage caused by an earthquake: A case study for Guadeloupe (France). Written communication, Feb 2005.

B. Lebrun, A.-M. Duval, P.-Y. Bard, O. Monge, M. Bour, S. Vidal, and H. Fabriol. Seismic microzonation: A comparison between geotechnical and seismological approaches in Pointeà-Pitre (French West Indies). Bulletin of Earthquake Engineering, 2(1):27-50, 2004. doi: 10.1023/B:BEEE.0000038949.91495.91.

K. W. Lin, D. J. Wald, C. B. Worden, and A. F. Shakal. Progress toward quantifying CISN Shakemap uncertainty. In Proceedings of the Eighth U.S. National Conference on Earthquake Engineering, 2006. Paper no. 1482.

F. Scherbaum, F. Cotton, and P. Smit. On the use of response spectral-reference data for the selection and ranking of ground-motion models for seismic-hazard analysis in regions of moderate seismicity: The case of rock motion. Bulletin of the Seismological Society of America, 94(6):2164-2185, Dec 2004. doi: 10.1785/0120030147.

K. T. Shabestari, F. Yamazaki, J. Saita, and M. Matsuoka. Estimation of the spatial distribution of ground motion parameters for two recent earthquakes in Japan. Tectonophysics, 390:193-204, 2004. doi: 10.1016/j.tecto.2004.03.031.

I. Suetomi, Y. Fukushima, E. Ishida, R. Isoyama, and S. Sawada. Estimation of detailed distribution of peak ground motion using observed records during the Niigata Chuetsu earthquake on October 23, 2004. In Proceedings of First European Conference on Earthquake Engineering and Seismology (a joint event of the 13th ECEE 83 30th General Assembly of the ESC), 2006. Paper number 346.

M. D. Trifunac and M. I. Todorovska. Evolution of accelerographs, data processing, strong motion arrays and amplitude and spatial resolution in recording strong earthquake motion. Soil Dynamics and Earthquake Engineering, 21(6):537-555, 2001.

D. J. Wald, B. C. Worden, V. Quitoriano, and K. L. Pankow. ShakeMap ® manual. Technical Manual, users guide, and software guide Version 1.0, Advanced National Seismic System, Jun 2006.

M. Wang and T. Takada. Macrospatial correlation model of seismic ground motions. Earthquake Spectra, 21(4):1137-1156, Nov 2005. doi: 10.1193/1.2083887.

D. L. Wells and K. J. Coppersmith. New empirical relationships among magnitude, rupture length, rupture width, rupture area, and surface displacement. Bulletin of the Seismological Society of America, 84(4):974-1002, Aug 1994. 


\section{List of Figures}

1 PGA from the Les Saintes earthquake predicted by various methods. Numbers correspond to the stations listed in Table 1 and the star indicates the epicentre.

$2 \mathrm{SA}(1.0 \mathrm{~s})$ from the Les Saintes earthquake predicted by various methods. Numbers correspond to the stations listed in Table 1 and the star indicates the

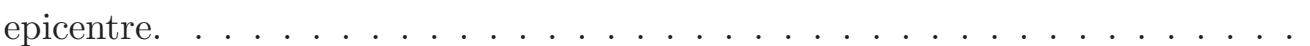

3 Standard deviations, estimated following Lin et al. (2006), of the ground motions from the Les Saintes earthquake predicted by kriging, the method of King et al. (2004) and the ShakeMap method. Numbers correspond to the stations listed in Table 1 and the star indicates the epicentre. . . . . . . . . . 


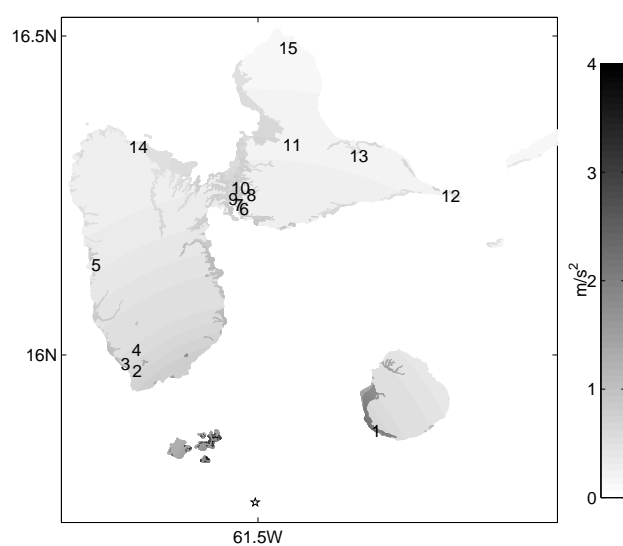

(a) Unadjusted Ambraseys et al. (2005) (rock) plus site effects

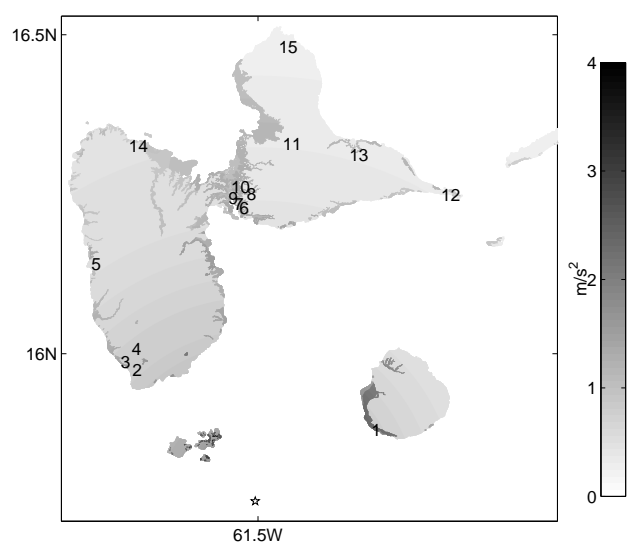

(c) Event-specific model (rock) plus site effects

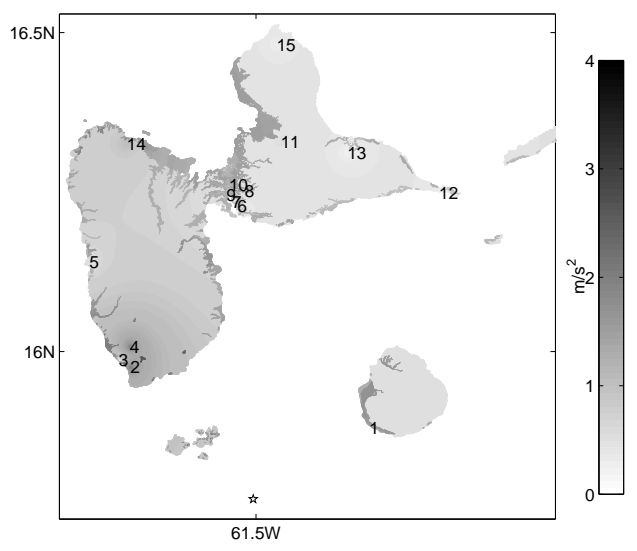

(e) Method of King et al. (2004)

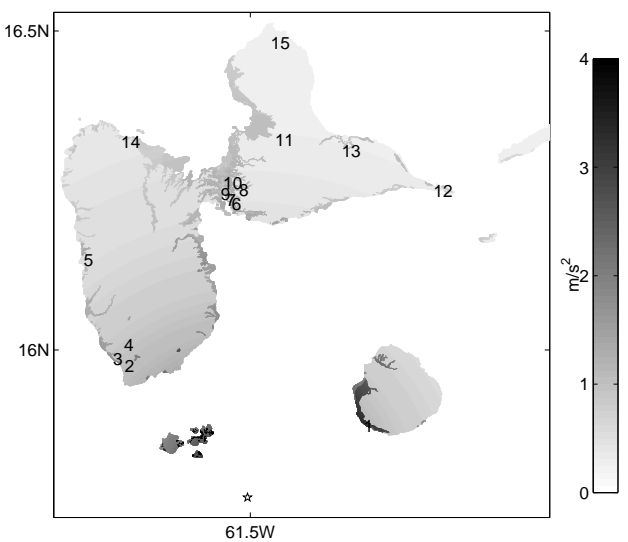

(b) Bias-corrected Ambraseys et al. (2005) (rock) plus site effects

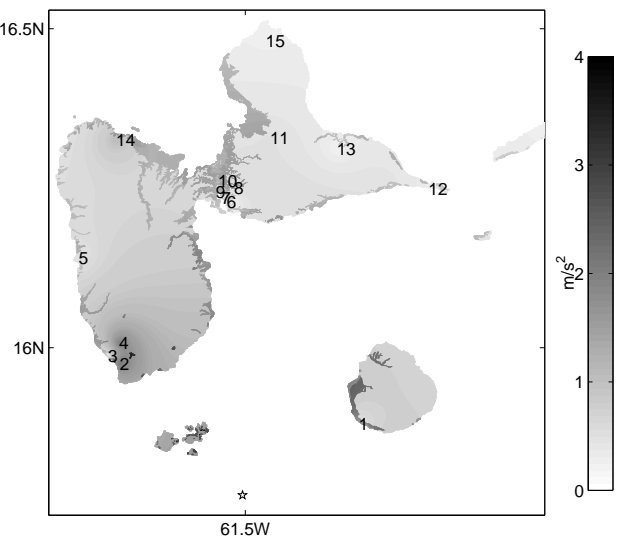

(d) Kriging

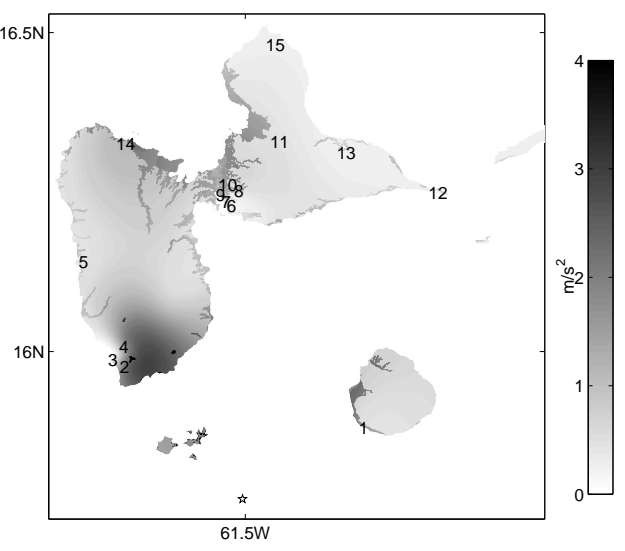

(f) Method of ShakeMap

Figure 1: PGA from the Les Saintes earthquake predicted by various methods. Numbers correspond to the stations listed in Table 1 and the star indicates the epicentre. 


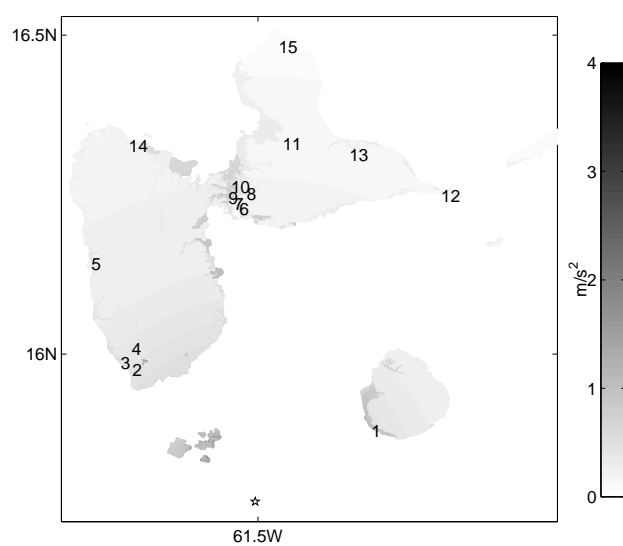

(a) Unadjusted Ambraseys et al. (2005) (rock) plus site effects

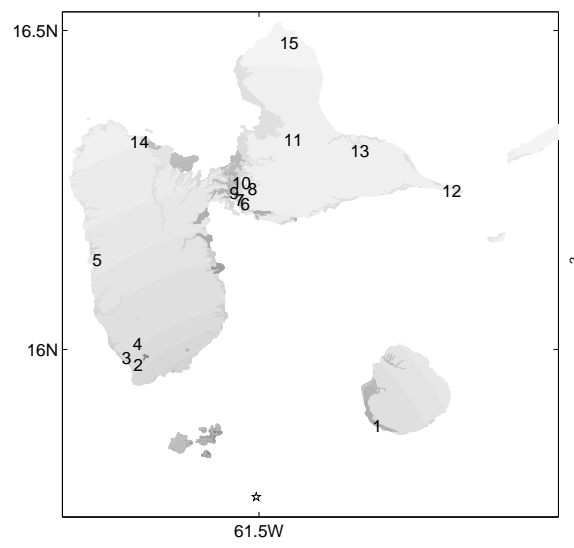

(c) Event-specific model (rock) plus site effects

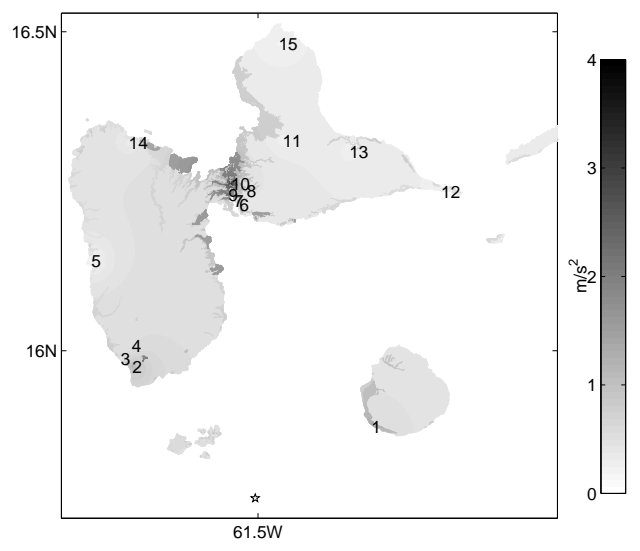

(e) Method of King et al. (2004)

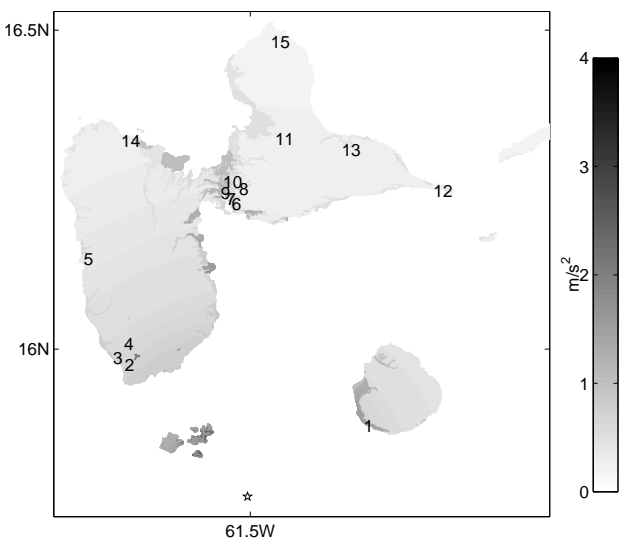

(b) Bias-corrected Ambraseys et al. (2005) (rock) plus site effects

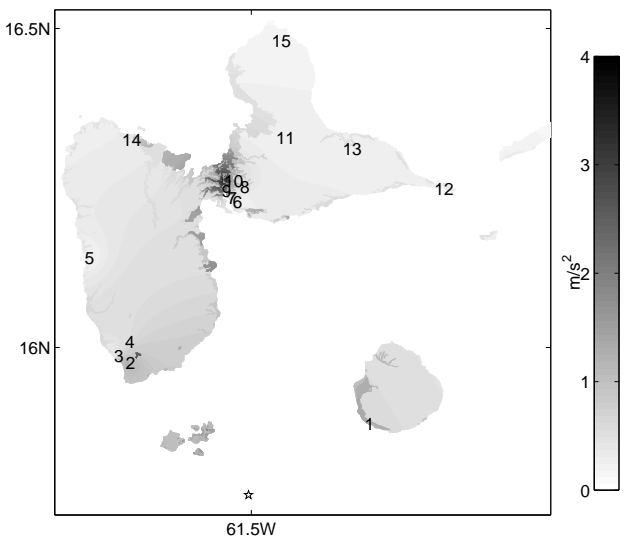

(d) Kriging

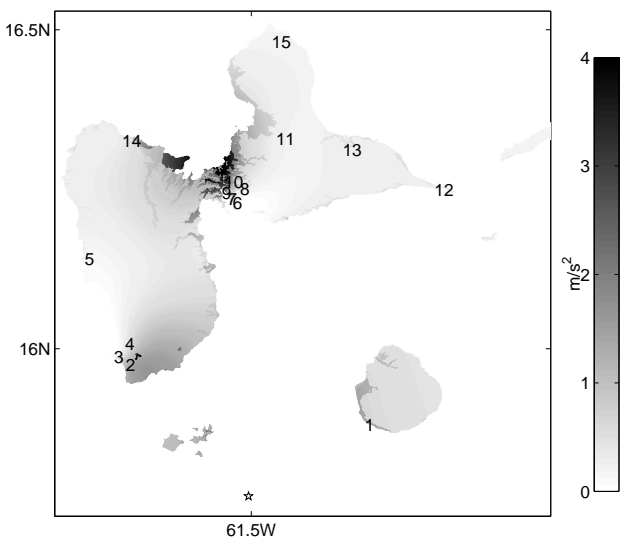

(f) Method of ShakeMap

Figure 2: SA(1.0s) from the Les Saintes earthquake predicted by various methods. Numbers correspond to the stations listed in Table 1 and the star indicates the epicentre. 


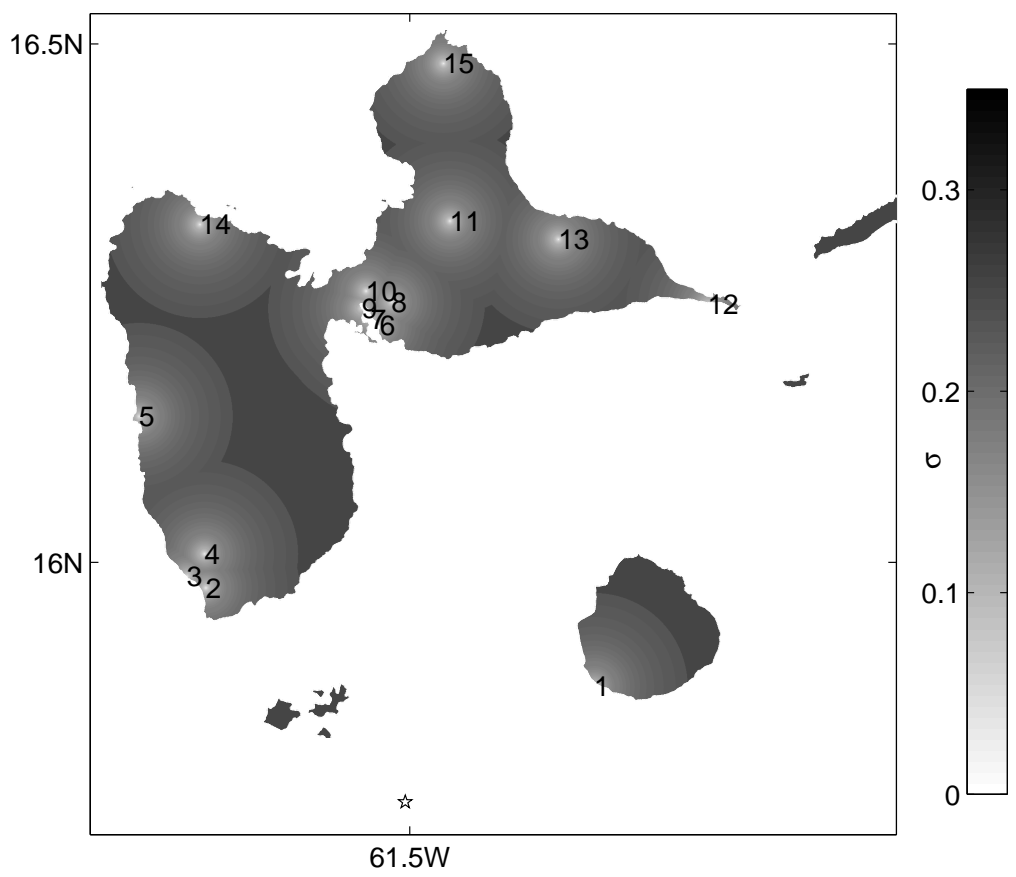

(a) PGA

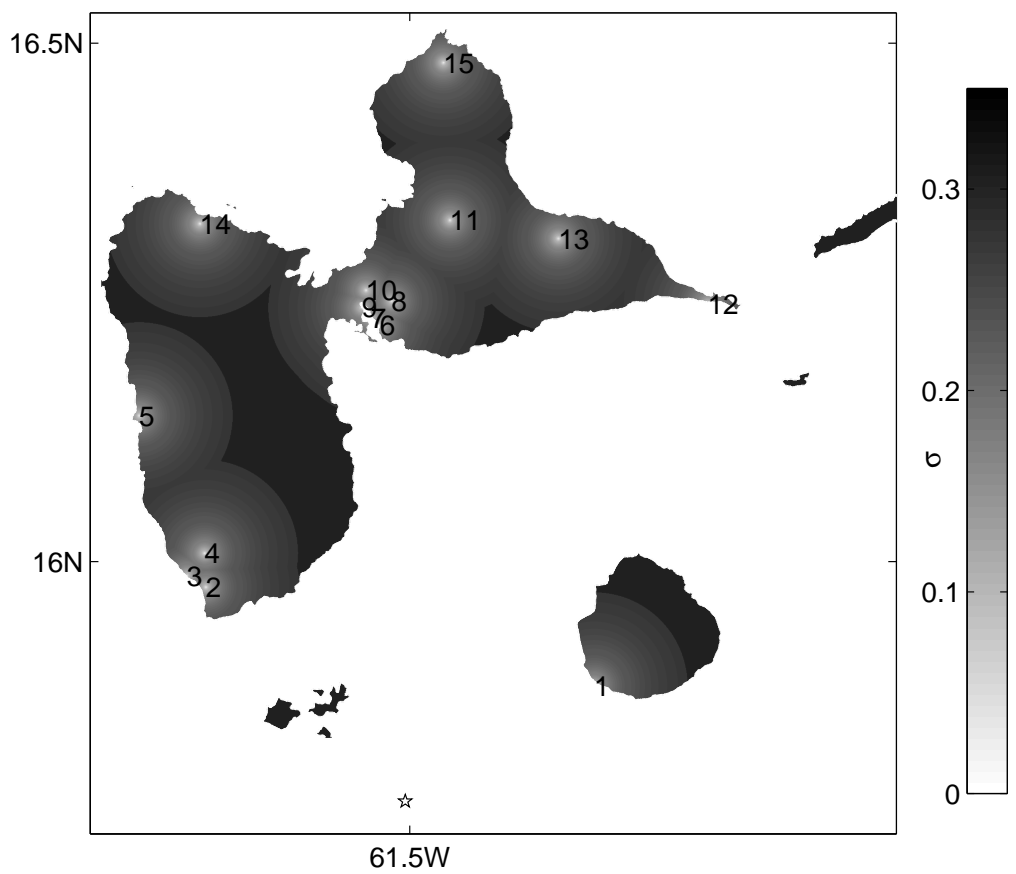

(b) $\mathrm{SA}(1.0 \mathrm{~s})$

Figure 3: Standard deviations, estimated following Lin et al. (2006), of the ground motions from the Les Saintes earthquake predicted by kriging, the method of King et al. (2004) and the ShakeMap method. Numbers correspond to the stations listed in Table 1 and the star indicates the epicentre. 